\title{
Tensile behavior and deformation mechanism of secondary generation single crystal superalloy DD6 at $1070^{\circ} \mathrm{C}$
}

\author{
Jian $\mathrm{Yu}^{\mathrm{a}^{*}}$, Jiarong $\mathrm{Li}^{\mathrm{b}}$, Shizhong $\mathrm{Liu}^{\mathrm{c}}$, Mei Han ${ }^{\mathrm{d}}$ and Zhenxue Shi ${ }^{\mathrm{e}}$ \\ Science and Technology on Advanced High Temperature Structural Materials Laboratory, Beijing \\ Institute of Aeronautical Materials, Beijing, China , 100095 \\ ayujianacademia@163.com, bjiarong.li@biam.ac.cn, ${ }^{c}$ biamlsz@yahoo.com.cn, \\ dmei.han2002@gmail.com, ${ }^{\mathrm{d}}$ shizhenxue@126.com
}

\begin{abstract}
Keywords: DD6; Single crystal superalloy; Tensile behavior; fractographs; Microstructures;
Abstract. The tensile behavior of secondary general single crystal superalloy DD6 with low Re was investigated at $1070^{\circ} \mathrm{C}$. In this study, orientation of the specimens was selected along the [001] direction and the evolution of microstructure and dislocation configurations were analyzed by SEM and TEM in detail. The results reveal that the stress - strain curves exhibit a curved feature, and fracture mechanism shows dimple model. After the tensile deformation at $1070^{\circ} \mathrm{C}$, the $\gamma^{\prime}$ phase morphology of DD6 alloy was maintained cubical. Due to the dissolution of $\gamma^{\prime}$ phase and tensile stress loaded at $1070^{\circ} \mathrm{C}$, the matrix channel is broadened. Consequently, the main deformation mechanism is that dislocations slip in matrix channels, and overcome the $\gamma^{\prime}$ phases through by-passing process.
\end{abstract}

\section{Introduction}

Nickel-based single crystal superalloys are widely used for the fabrication of critical components of aero-engine such as turbine blades and vanes because of their excellent resistance to high temperature deformation [1-5]. The outstanding high temperature mechanical strength of these alloys benefits from the additions of a number of refractory alloying elements. The main advance in this field was the introduction of Rhenium ( $R e$ ) as a new alloying element, leading to exhibit improved creep, fatigue and tensile properties as compared to the first generation single crystal alloys, which do not contain Re addition [6]. The DD6 alloy was developed for the applications of turbine blade on aero-engine. Although the properties of the alloy are equivalent to those of other second generation single crystal superalloys, DD6 alloy is a low cost second generation single crystal superalloy with only $2 \mathrm{wt} . \% \operatorname{Re}[7$, 8].

The purpose of this study is to evaluate the tensile behavior and deform mechanism of DD6 alloy with low Re at high temperature. In this work, we concentrate on the evolution of the microstructures and the dislocation structures during the tensile test, and try to explore the deformation mechanism of secondary generation single crystal superalloy with low Re at high temperature.

\section{Material and Experiment procedure}

The material investigated in this work is DD6 single crystal superalloy. The nominal chemical composition (weight fraction, \%) of the DD6 alloy used in this work was : Cr 4.3, Co 9 , Mo 2 , W 8, Ta 7.5 , Re 2 , Nb 0.5 , Al 5.6 , Hf 0.1 , C 0.006 , Ni Bal.[7, 8]. The single crystal bars of DD6 alloy were directionally solidified in a Bridgman furnace using seed technique. The initial orientation of the single crystal bars was determined by the X-ray diffraction. In this study, Longitudinal orientation of the specimen was within $5^{\circ}$ deviation from the [001] direction.

The single crystal bars received a standard heat treatment, which is listed as follow: $1290^{\circ} \mathrm{C} / 1$ hour + $1300^{\circ} \mathrm{C} / 2$ hours $+1315^{\circ} \mathrm{C} / 4$ hours/AC $+1120^{\circ} \mathrm{C} / 4$ hours/AC $+870^{\circ} \mathrm{C} / 32$ hours/AC. Fig. 1 is the microstructures of DD6 alloy after this heat treatment. The $\gamma^{\prime}$ partials exhibit optimized size and distribution; and the mean width of matrix channel is $0.08 \mu \mathrm{m}$. After this standard heat treatment, the 
tensile specimens were machined from bars with the gauge length of $25 \mathrm{~mm}$ and the diameter of $5 \mathrm{~mm}$. Then the tensile tests were performed at the temperature of $1070^{\circ} \mathrm{C}$ by the reference of $\mathrm{HB} 5195$.

The microstructure and dislocations of a specimen that had been stretched to rupture was analyzed as a function of the distance to the fracture surface in longitudinal and transverse sections. Microstructures of tensile specimen were examined by scanning electron microscope (SEM). Thin foil for transmission electron microscopy (TEM) analysis was prepared by twin-jet polishing method. TEM analysis was focused on cross-sectioned parallel to low-index crystallographic near and remote area comparing to the fracture surfaces. The resulted foil was examined by a FEI Tecnai G20 TEM operated at $200 \mathrm{kV}$.

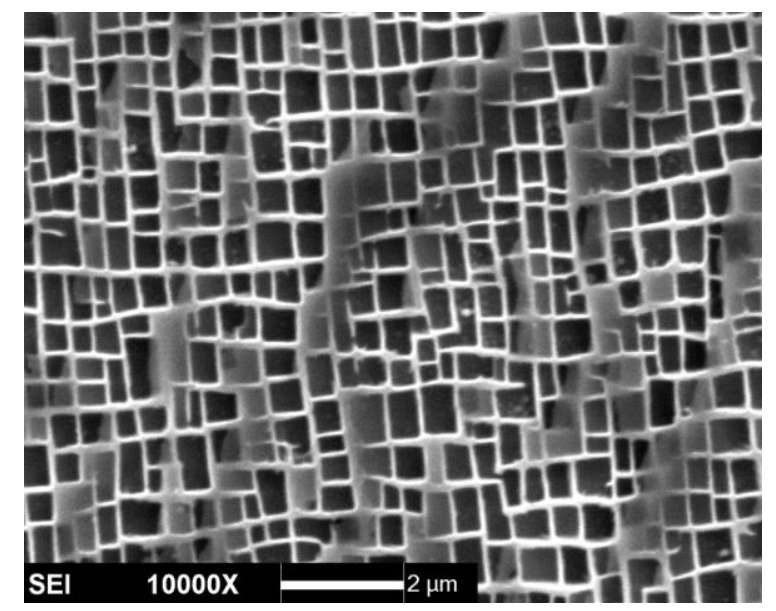

Fig. 1 Microstructure of DD6 alloy after heat treatment

\section{Result and discussion}

Tensile behavior. Fig. 2 shows stress-strain curves acquired at the $1070^{\circ} \mathrm{C}$ temperature. The flow stress of DD6 alloy exhibit a curved feature, and the alloy did not show a well-defined yield point. The stress increased dramatically to the peak point, and then slightly dropped. The stress-strain curves of DD6 alloy in tensile at the $1070^{\circ} \mathrm{C}$ exhibits similar features with other alloys, which contain $4.2 \mathrm{wt} . \%$ Re [9]. According to the stress-strain curves, the DD6 alloy with low Re possesses excellent strength and plasticity at high temperature. The ultimate tensile strength and yield strength of DD6 alloy are $572 \mathrm{MPa}$ and $455 \mathrm{MPa}$, respectively. The elongation of DD6 alloy after tensile is $20.5 \%$.

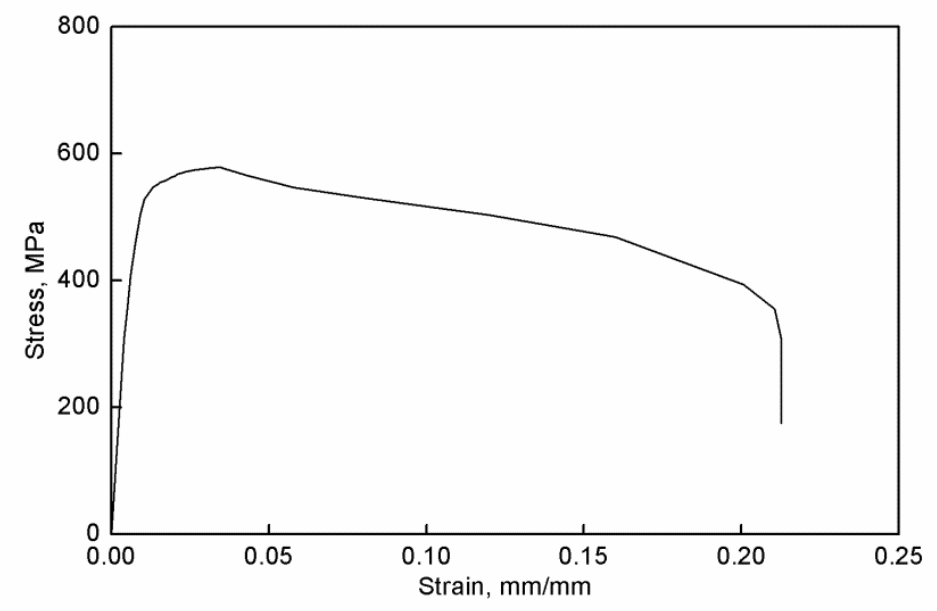

Fig. 2 Stress-strain curve of DD6 alloy at $1070^{\circ} \mathrm{C}$ 
Fracture surface. Fig. 3(a) and 3(b) show the fracture surface of DD6 alloy along [001] direction after the tensile at $1070^{\circ} \mathrm{C}$. The necking can be observed near the fracture surface. The morphology of the fracture surface indicated that the fracture of DD6 alloy at high temperature is the dimple fracture mode, as shown in Fig. 3(a). The numerous cracks can be observed on the fracture surface, as shown in Fig. 3(b). The cracks appeared as rectangular, planar features, and the majority of cracks are associated with micro-pores. Fig. 3(c) shows the morphology of the necking region near the fracture surface in longitudinal section. It can be observed that the cracks generated from the micro-pores, and extended along with the interfaces of the $\gamma / \gamma^{\prime}$ phases, which also indicates that the cracks are associated with micro-pores.
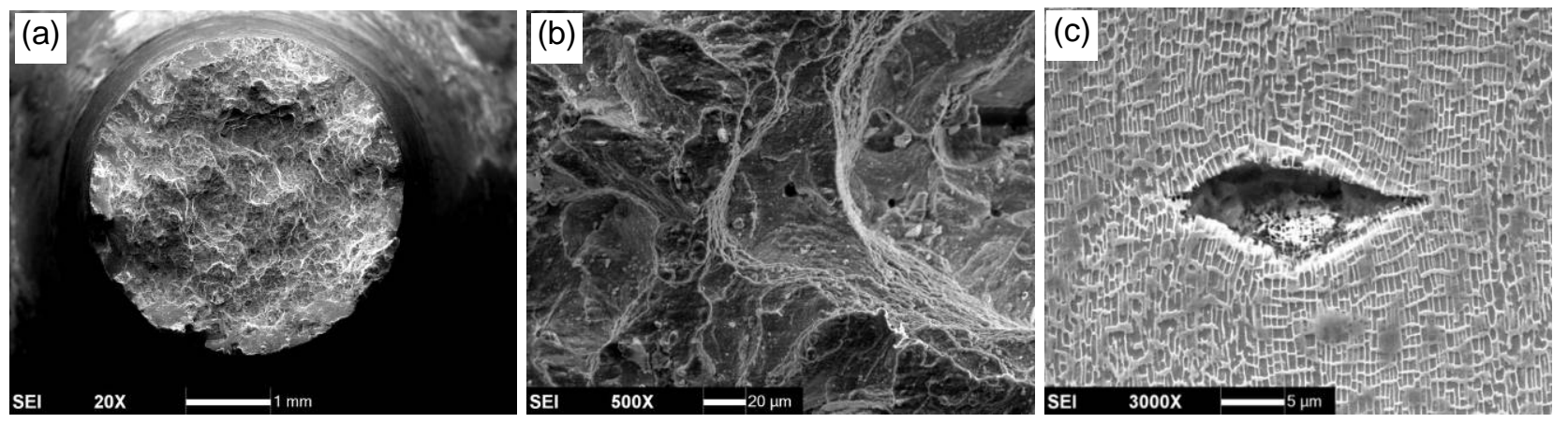

Fig. 3 Fracture surface and morphology of longitudinal section of DD6 alloy after the tensile at $1070^{\circ} \mathrm{C}$

(a) Fracture surface, (b) enlarged image of (a); and (c) morphology of longitudinal section

Evolution of microstructure. Fig. 4 shows the microstructures on the cross section and longitudinal section of DD6 alloy after the tensile at $1070^{\circ} \mathrm{C}$. In Fig. 4(a) and 4(b), the morphology of $\gamma^{\prime}$ phase in DD6 alloy was maintained cubical. Since the $\gamma^{\prime}$ phase slightly dissolved at $1070^{\circ} \mathrm{C}$, the matrix channels are broadened.
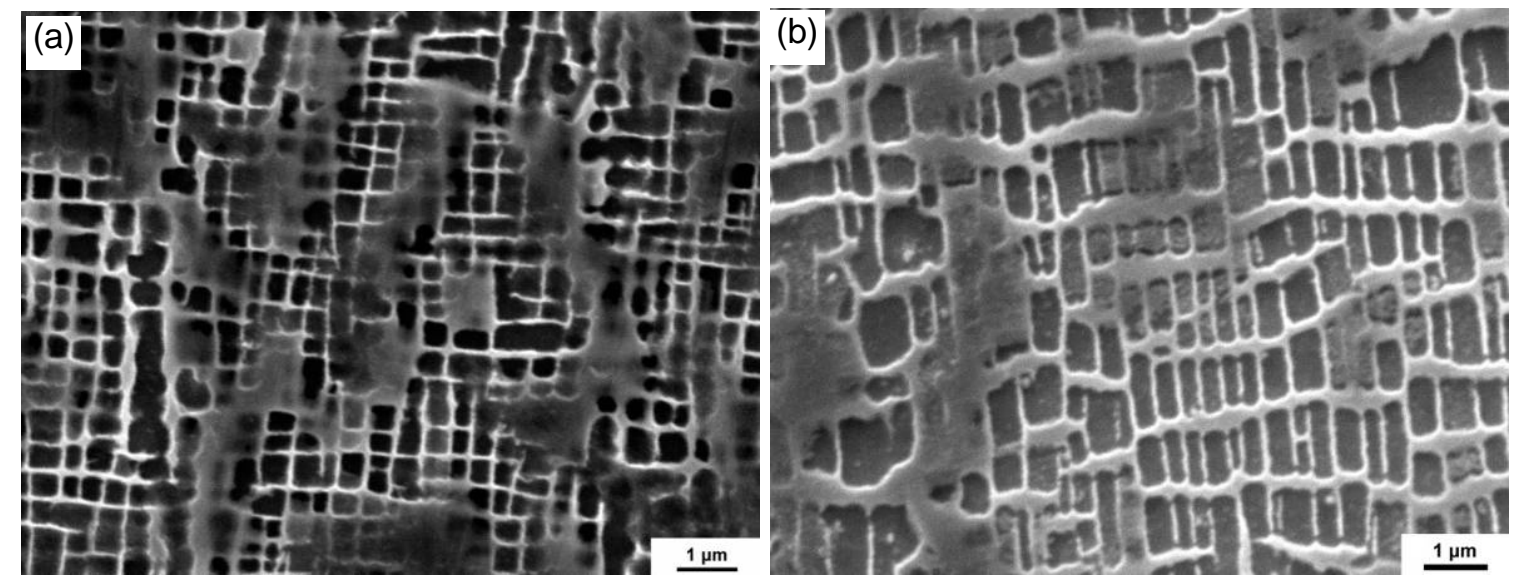

Fig. 4 Microstructures of DD6 alloy after the tensile at $1070^{\circ} \mathrm{C}$

(a) Cross section, and (b) longitudinal section

Fig. 5 shows the SEM images of dendrites on the longitudinal sections with different distances to the fracture surface in the ruptured specimen of DD6 alloy after the tensile at $1070^{\circ} \mathrm{C}$. With the distance to fracture surface decreased, the vertical matrix channels which are parallel to load axis remained the same; while the width of horizontal matrix channels which are perpendicular to load axis are increased. The width of horizontal matrix channels and vertical matrix channels on a longitudinal section of the failed specimen are plotted as functions of distance to the fracture surface, as shown in Fig. 6. It can be measured that the mean width of vertical matrix channels is $0.115 \mu \mathrm{m}$. The width of horizontal matrix channels is increased from $0.118 \mu \mathrm{m}$ to $0.203 \mu \mathrm{m}$, as the distance is closed to fracture surface. 
Compared to the width of vertical matrix channels, the width of horizontal matrix channels are gradually increased because of the load of tensile stress.
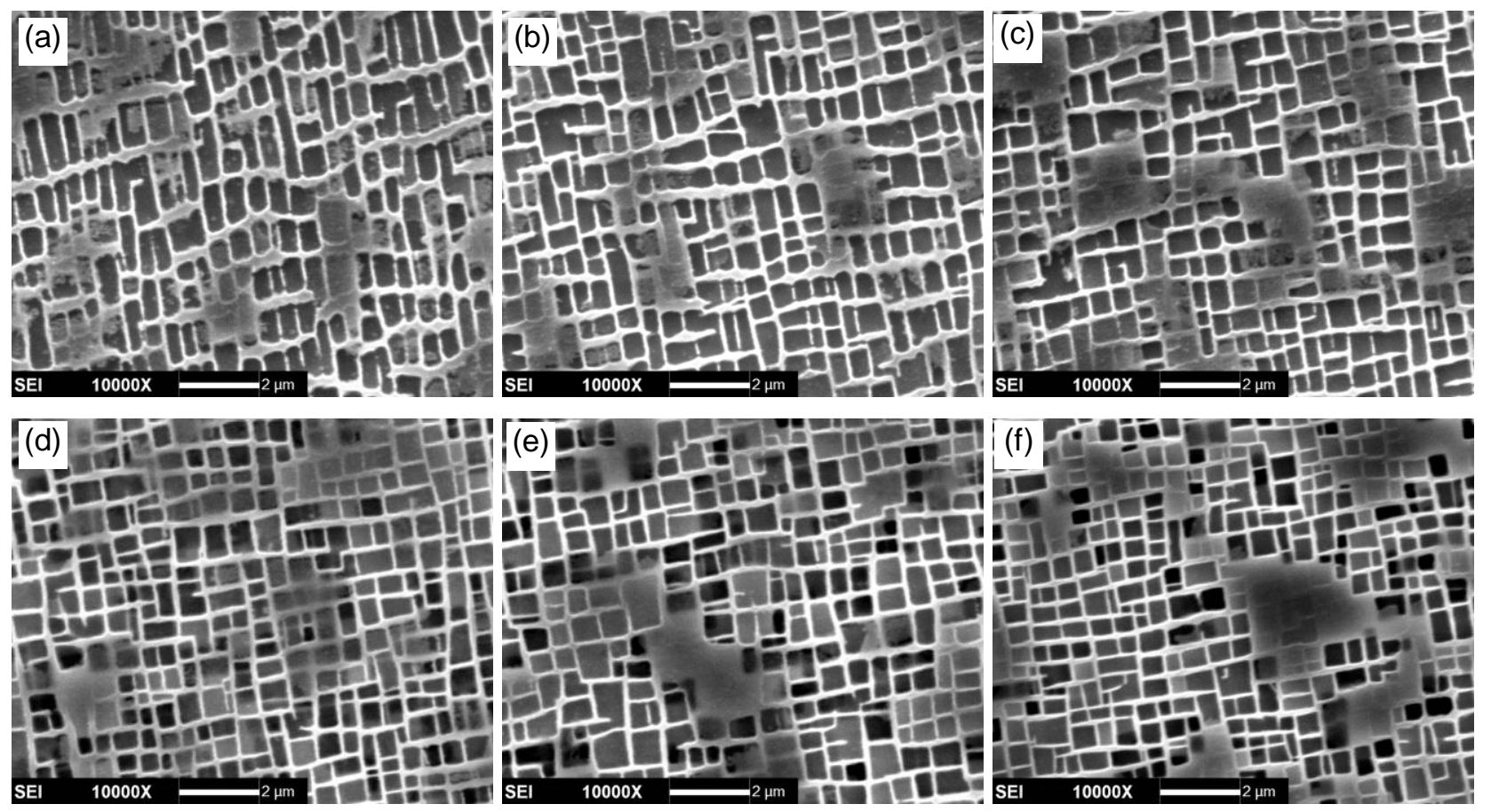

Fig. 5 Microstructure of longitudinal section of DD6 alloy as functions of their distance from the fracture surface

(a) $1 \mathrm{~mm}$, (b) $4 \mathrm{~mm}$, (c) $11 \mathrm{~mm}$, (d) $18 \mathrm{~mm}$, (e) $31 \mathrm{~mm}$, and (f) $40 \mathrm{~mm}$

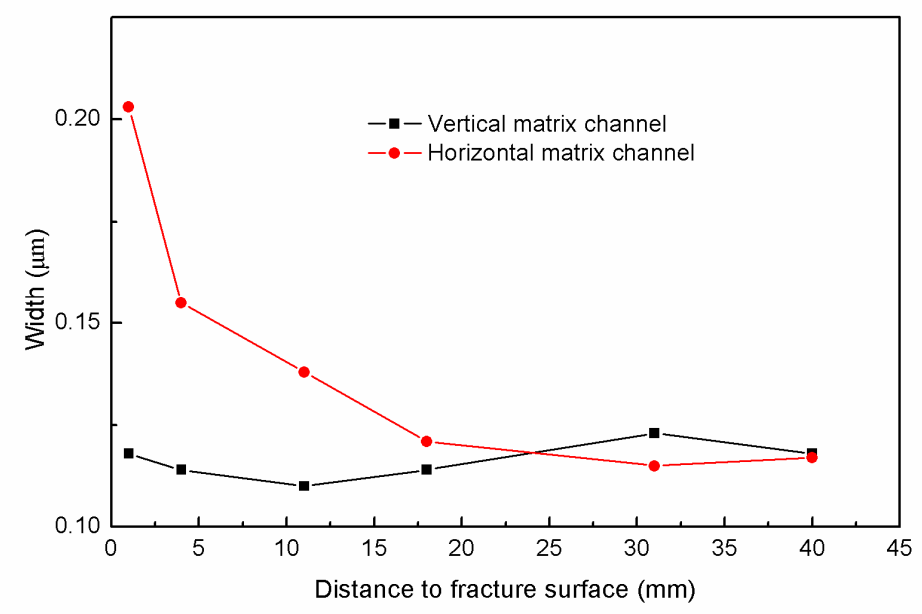

Fig. 6 Width of matrix channel as function of their distance to fracture surface

Evolution of dislocation. Fig. 7(a) and 7(b) show the dislocation configuration of cross section about $18 \mathrm{~mm}$ and $4 \mathrm{~mm}$ away from the fracture surface, respectively. For the distance of $18 \mathrm{~mm}$ away from the fracture surface, numerous dislocations can be observed in the $\gamma$ matrix channel, but no dislocations in the $\gamma^{\prime}$ phase, as shown in Fig. 7(a). The microstructure of this area of the failed specimens can be regarded as the initial stage of the tensile behavior. For the distance of $4 \mathrm{~mm}$ away from the fracture surface, network of dense dislocation can be observed in the $\gamma / \gamma^{\prime}$ interfaces, but nearly no dislocations in the $\gamma^{\prime}$ phase, as shown in Fig. 7(b). The dislocation configuration of DD6 alloy after the tensile at the $1070^{\circ} \mathrm{C}$ exhibits similar features with other secondary general single crystal superalloys. In previous studies of secondary general single crystal superalloys [10-13], it has been demonstrated that the 
Burgers vector of dislocations in matrix channels is $a / 2<011>$, which indicated that the $<011>\{111\}$-type slip systems were activated during tensile tests of DD6 alloy at high temperature.

The network of intensive dislocation on $\gamma / \gamma^{\prime}$ interfaces can effectively prevent the dislocation from cutting through $\gamma^{\prime}$ phases. Due to the $\gamma^{\prime}$ phase dissolution and the stress load, the matrix channels are broadened, as shown in Fig. 4-6, which assisted the movement of the dislocations slip in the matrix channels. Therefore the main deformation mechanism is dislocations slip in matrix channels and overcome $\gamma^{\prime}$ phases through by-passing process according to the dislocations configuration.
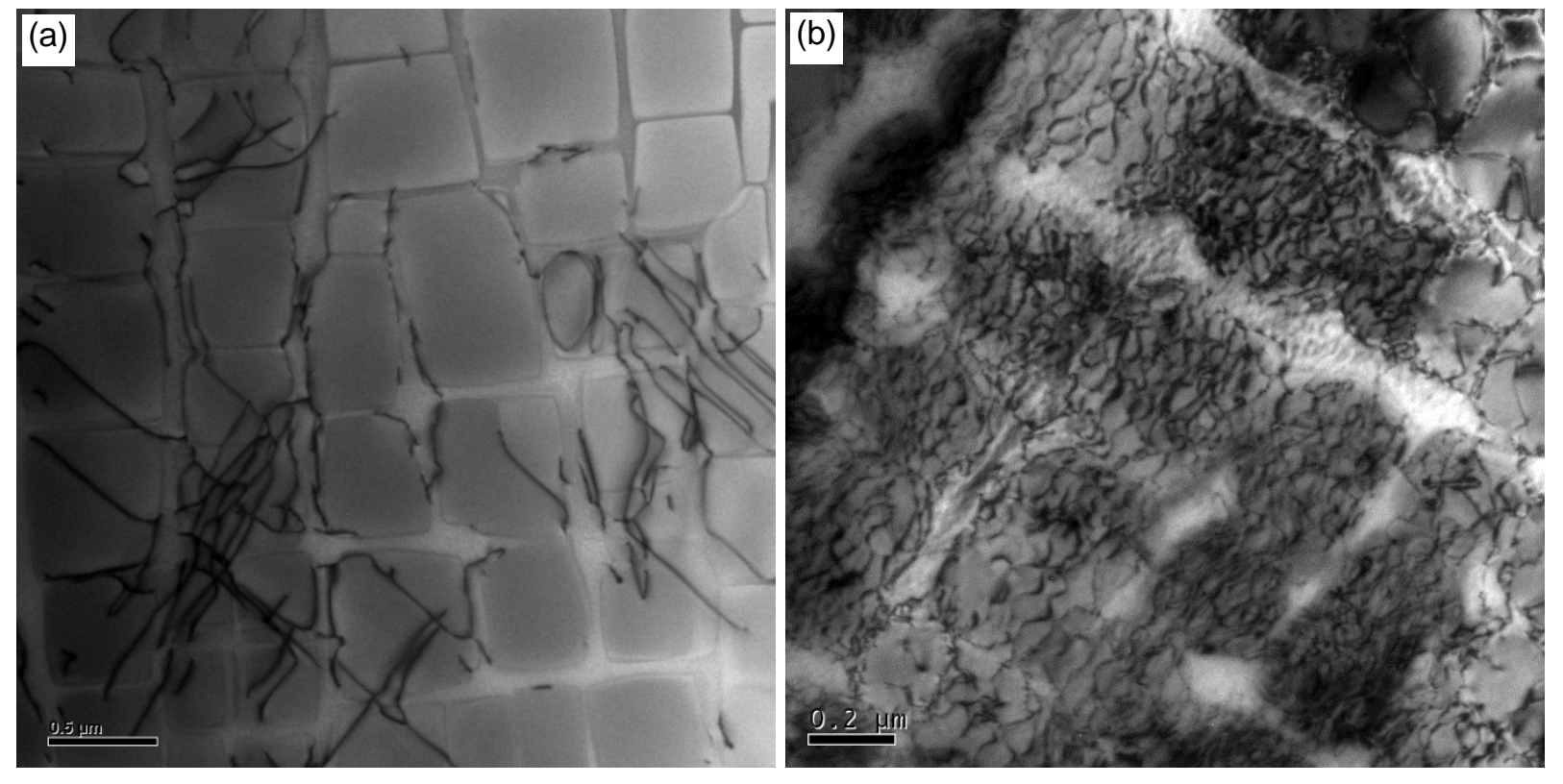

Fig. 7 TEM images of DD6 alloy after the tensile at $1070^{\circ} \mathrm{C}$

(a) $18 \mathrm{~mm}$ to fracture surface, and (b) $4 \mathrm{~mm}$ to fracture surface.

\section{Conclusions}

In this study, the tensile curve and microstructure of DD6 alloy along [001] orientation after the tensile at $1070^{\circ} \mathrm{C}$ were investigated. Several conclusions can be drawn from this study as follows:

(1) The stress - strain curves of DD6 alloy tensile at $1070^{\circ} \mathrm{C}$ exhibit a curved feature, and fracture mechanism is dimple model.

(2) The $\gamma^{\prime}$ phase of DD6 alloy was slightly dissolved at $1070^{\circ} \mathrm{C}$. The matrix channels are broadened because of the dissolution of $\gamma^{\prime}$ phase and the loaded stress.

(3) Network of dense dislocation is observed in the $\gamma / \gamma^{\prime}$ interfaces, and no dislocations in the $\gamma^{\prime}$ phase, therefore the dominate deformation mechanism is dislocations slip in matrix channel and overcome $\gamma^{\prime}$ phases through by-passing process.

\section{Acknowledgements}

The authors would like to acknowledge TEM technology support by Beijing National Center for Electron Microscopy.

\section{References}

[1] R.C. Reed, Superalloys: fundamentals and applications, Cambridge University Press, Cambridge, 2006.

[2] W. Betteridge, S.W.K. Shaw, Development of suoeralloys. Mater. Sci. Technol., 3 (1987) 682-694. 
[3] C.T. Sims, N.S. Stoloff, W.C. Hagel, Superalloy ( $\square$ ), John Wiley \& Sons, Inc., New York, 1987.

[4] J. Yu, J.R. Li, Z.X. Shi, J.Q. Zhao, S.Z. Liu, M. Han, Microstructural Evolution of the [001] Oriented Single Crystal Superalloy DD6 Creep at $760^{\circ} \mathrm{C}$ and $785 \mathrm{MPa}$. Advanced Materials Research, 535-537 (2012) 888-893.

[5] J. Yu, J.R. Li, J.Q. Zhao, M. Han, Z.X. Shi, S.Z. Liu, H.L. Yuan, Orientation dependence of creep properties and deformation mechanism in DD6 single crystal superalloy at $760^{\circ} \mathrm{C}$ and $785 \mathrm{MPa}$. Mater. Sci. Eng. A, 560 (2013) 47-53.

[6] C.M.F. Rae, R.C. Reed, Primary creep in single crystal superalloys: Origins, mechanisms and effects. Acta Mater., 55 (2007) 1067-1081.

[7] J.R. Li, J.Q. Zhao, S.Z. Liu, M. Han, Effects of Low Angle Boundaries on the Mechanical Properties of Single Crystal Superalloy DD6, in: R.C. Reed, K.A. Green, P. Caron, T.P. Grab, M.G. Fahrmann, E.S. Huron, S.A. Woodard (Eds), Superalloys 2008. TMS, Warrendale, PA, 2008, pp. 443-451.

[8] J.R. Li, Z.G. Zhong, D.Z. Tang, S.Z. Liu, P. Wei, P.Y. Wei, Z.T. Wu, D. Huang, M. Han, A Low-cost Eecond Geneution Single Crystal Superalloy DD6, in: T.M. Pollock, R.D. Kissinger, R.R. Bowman, K.A. Green, M. Mclean, S. Olson, J.J. Schina (Eds), Superalloys 2000. TMS, Warrendale, PA, 2000, pp. 777-783.

[9] J.L. Liu, J.J. Yu, T. Jin, X.F. Sun, H.R. Guan, Z.Q. Hu, Influence of temperature on tensile behavior and deformation mechanism of Re-containing single crystal superalloy. Trans. Nonferr. Metal. Soc. China, 21 (2011) 1518-1523.

[10] W.W. Milligan, S.D. Antolovich, Yielding and deformation behavior of the single crystal superalloy PWA 1480. Metal. Trans. A, 18 (1987) 85-95.

[11] W.W. Milligan, S.D. Antolovich, The correlation between the temperature dependence of the CRSS and the formation of superlattice-intrinsic stacking faults in the nickel-base superalloy PWA 1480. Metal. Trans. A, 20 (1989) 1888-1889.

[12] W.W. Milligan, S.D. Antolovich, The Mechanism and temperature dependence of superlattice stacking fault formation in the single-crystal superalloy PWA 1480. Metal. Trans. A, 22 (1991) 2309-2318.

[13] R.C. Reed, N. Matan, D.C. Cox, M.A. Rist, C.M.F. Rae, Creep of CMSX-4 superalloy single crystals: effects of rafting at high temperature. Acta Mate., 47 (1999) 3367-3381. 